\title{
Cardiac Anomalies in Liveborn and Stillborn Monochorionic Twins
}

\author{
Elizabeth McPherson, MD; Colin Korlesky, BS; and Scott Hebbring, PhD
}

\begin{abstract}
Background: Cardiovascular anomalies are more common in monochorionic twins, especially with twin-twin transfusion, compared to other twin types and to singletons. Because previous studies are based on fetal and neonatal echocardiography, more information is needed to study prevalence of cardiac anomalies in twin miscarriages, stillbirths, and children after the immediate neonatal period.
\end{abstract}

Methods: With specific attention to cardiac anomalies, we reviewed the medical records of 335 selected liveborn twin pairs from the Marshfield Clinic Twin Cohort (enriched for twin-twin transfusion) and all twins (I75 pairs) identified in the Wisconsin Stillbirth Service Program cohort of late miscarriages and stillbirths.

Results: Structural cardiac defects occurred in 12\% of liveborn monochorionic twin infants and $7.5 \%$ of stillborn infants with twin-twin transfusion compared to only $2 \%$ of liveborn dizygotic twins and no stillborn dizygotic infants. The most common cardiac lesion in liveborn twins was ventricular septal defect, which was usually isolated and discordant, preferentially affecting the smaller twin in monochorionic pairs. Among stillborn and miscarried monochorionic twins, the most common cardiac lesion was acardia.

Conclusions: Monochorionic twins, particularly those with TTT, are at increased risk for a spectrum of structural cardiac malformations which we suggest may be related to asymmetry of the inner cell mass resulting in a smaller poorly perfused twin. In severe cases, limited cardiac and circulatory development in the affected twin leads to acardia. In less severe cases, the smaller infant has deficient septal growth that sometimes results in ventricular septal defect.

Keywords: Cardiac abnormalities; Ventricular septal defect; Twin-twin transfusion

$\mathrm{C}$ ompared to singletons and dichorionic (DC) twins, monochorionic (MC) twins, particularly pairs with twin-twin transfusion (TTT), are at increased risk for developing cardiac anomalies. ${ }^{1-7}$ In addition to abnormalities caused by the hemodynamic consequences of unequal blood flow, such as cardiomegaly and right outflow tract obstruction (ROTO), fetal echocardiography studies of MC twins reveal increased frequency of structural cardiac defects. ${ }^{1-8}$ Because concordance in $\mathrm{MC}$ pairs is relatively low, ranging from
$26.7 \%$ for any structural cardiac defect ${ }^{2}$ to $18 \%$ for flow lesions and $7 \%$ for conotruncal defects, ${ }^{5}$ the cause of structural cardiac defects in MC twins is unlikely to be monogenic.

Previous studies have suggested several reasons for discordant cardiac lesions in MC pairs. Cardiac problems related to circulatory overload such as ROTO occur exclusively in recipients of $\mathrm{TTT}^{1-3}$ and often improve following fetoscopic laser therapy. ${ }^{9,10}$ Herberg et a ${ }^{10}$ found pulmonic stenosis only
Corresponding Author: Elizabeth McPherson, MD, Center for Human Genetics, Marshfield Clinic Research Institute, 1000 N. Oak Avenue, Marshfield, WI 54449, Tel: (7I5) 615-5522, Email: mcpherson.elizabeth@marshfieldresearch.org
Received: December 20, 2018

Revised: July 25, 2019

2nd revision received: August 27, 2019

3 rd revision received: October 3, 2019

Accepted: October 17, 2019

doi: $10.3121 / \mathrm{cmr} .2019 .1478$ 
in recipient twins, while atrial septal defects (ASD) occurred at similar frequencies in donors and recipients. Van den Boom et $\mathrm{al}^{11}$ reported increased frequency of coarctation of the aorta among donor twins in pairs with severe TTT, suggesting that aortic coarctation may be an effect of hypovolemia. Al Rais et $\mathrm{al}^{6}$ discovered ROTO and mitral dysplasia exclusively in TTT recipients, but in pairs without TTT, a variety of cardiac abnormalities were noted, mostly in the smaller twin. These observations suggest that ROTO, pulmonic stenosis, and mitral dysplasia in the recipient and possibly coarctation of the aorta in the donor result from unequal perfusion, while ASD and other cardiac malformations presumably have different causes.

Since MC twin embryos develop in close proximity, even minor differences in developmental timing could allow laterality determining signaling pathways to function normally in one member of an MC pair while disrupting laterality development of the co-twin. Observations of increased heterotaxy, atrial isomerism, and looping defects affecting only one member of an MC pair support this hypothesis. ${ }^{6}$ Concordance of $\mathrm{MC}$ pairs for laterality defects is rare, although Thacker et $\mathrm{al}^{12}$ reported an interesting monozygotic (MZ) pair with right- and left-sided isomerism, respectively.

Another possible mechanism for discordant cardiac anomalies in MC twins is asymmetry of the inner cell masses. ${ }^{13}$ Discordant growth of the inner cell masses with corresponding changes in growth factor expression were observed by Noli et al. ${ }^{14}$ Benirschke ${ }^{15}$ pointed out that unequal division of the inner cell mass can initiate a sequence of delayed cardiac development leading to lower blood pressure and decreasing placental share for the smaller twin, who then presents later in pregnancy as the "donor" in TTT. In more severe cases, this "donor" twin may develop reversed circulation and degenerate to an acardiac fetus. Asymmetric growth of the fetuses and their placentae with deceased angiogenesis in the smaller twin may also contribute to cardiac malformations in the smaller twin, even without evidence of TTT. ${ }^{4}$ This could also account for the increased prevalence of cardiac anomalies in both $\mathrm{MZ}$ and DZ twins observed by Herskind et al, in the Danish Twin Registry. ${ }^{16}$

Studies based on prenatal echocardiography leave gaps in understanding cardiac defects in twins at both ends of the severity spectrum. Without autopsy-based studies of twin miscarriages, cardiac defects that cause demise prior to 20 weeks are missed. Less severe cardiac anomalies such as ASD and small ventricular septal defects (VSD), which are difficult to diagnose on fetal echocardiography, may also be underestimated in the absence of long-term follow-up. In one of the few studies with follow-up after the immediate neonatal period, Herberg et $\mathrm{al}^{10}$ found structural cardiac malformations in 10/89 survivors of laser surgery for TTT. Analysis of cardiac anomalies in stillborn twin and liveborn twin cohorts with long-term follow-up data may contribute to understanding of the full spectrum of cardiac defects present in twin pairs and suggest novel mechanisms for the development of cardiac abnormalities in twin pregnancies.

During an unrelated study of renal disease, detailed manual medical record review of all twin pairs with an ICD9 or ICD10 coded diagnosis of twin-twin transfusion in the Marshfield Clinic Twin Cohort (MCTC) yielded an incidental finding of VSD in 5/39 (4 donors and 1 recipient). Because this was a much higher prevalence of VSD's than observed in previous studies of congenital heart disease in twins, we decided to perform a similarly detailed manual record review in larger samples of same sex and opposite sex twins from the MCTC. Because the MCTC includes only liveborn pairs, TTT is likely underrepresented, so we also manually reviewed the records of all twin pairs referred to the Wisconsin Stillbirth Service Program for etiologic evaluation looking for differences in the types and prevalence of congenital cardiac malformations between the MCTC cohort, our stillborn cohort, and the published, primarily perinatal cohorts.

\section{Materials and Methods}

The Marshfield Clinic Twin Cohort (MCTC) is composed of 8,722 presumed twin pairs identified based on last name, birthdate, address, billing accounts, and/or natural language processing from 30 years of electronic health records (EHR) ${ }^{17}$ These are liveborn individuals with follow-up from 1 to 30 years. During a previous study, electronic query for ICD9 and ICD10 codes indicating TTT revealed 39 pairs, each with TTT confirmed by manual record review. For each of the initial 39 TTT pairs, four additional same sex and four opposite sex pairs (matched for age, duration of medical record available and gender of same sex pairs) were selected for further study. Manual of the entire medical record of these additional cases identified an additional 6 TTT cases, $17 \mathrm{MZ}$ pairs with no evidence of TTT (based on monochorionicity and/or zygosity testing), and $6 \mathrm{DZ}$ pairs (discordant for genetic disorders) among the selected same sex pairs. Sixteen pairs proved not to be twins on detailed review and were excluded. The medical records of the 335 remaining twin pairs (45 TTT, 17 other MZ, $149 \mathrm{DZ}$, and 124 same sex pairs of unknown zygosity [UZ]) were manually reviewed with specific attention to cardiac anomalies, other birth defects, and growth parameters (Figure 1A). Incomplete records were evaluated on the basis of available data. Cardiac anomalies were diagnosed by echocardiography during routine care, usually after a murmur was heard. Structural defects such as VSD or valvular pulmonic stenosis identified by echocardiography were counted, regardless of whether surgery was required. Transient peripheral pulmonic stenosis, patent foramen ovale, and/or patent ductus in preterm infants were not counted as structural heart disease. Infants with neonatal echocardiograms showing biventricular or right ventricular hypertrophy or clinically significant cardiomyopathy were combined under the term "cardiomegaly/cardiomyopathy." 
The Wisconsin Stillbirth Service Program (WiSSP) database of 3,137 stillbirths and second trimester miscarriages referred for etiologic evaluation between 1983 and 2017 includes 175 twin gestations in which one or both twins died during the second or third trimester. Of these, 95 pairs were identified as MZ (primarily on the basis of monochorionicity), 2 pairs were identifiable as DZ due to opposite gender, and the zygosity of the remaining 56 pairs was unknown (Figure 1B). All records submitted at the time of initial evaluation (maternal records, photographs, radiographs, placental pathology reports, autopsy, and chromosomal or other genetic studies) were reviewed with particular attention to cardiac anomalies, other birth defects, and growth parameters. Incomplete records were evaluated on the basis of available data. Structural cardiac anomalies were diagnosed by autopsy, except in two cases identified prenatally by fetal echocardiography without postmortem evaluation of the heart. Pairs with abnormalities attributable to unequal perfusion such as polyhydramnios/ oligohydramnios, marked discrepancy in cardiac weight, twintwin disruption (TTD), and twin arterial reversed perfusion/ acardia were included in the TTT/TTD category whether or not placental anastomoses were studied. Very small amorphic or acephalic fetuses were counted in the "acardiac" category. Cardiomegaly was diagnosed based on heart weight above the 95th percentile at autopsy using the standards of Maroun \& Graem ${ }^{18}$ or description of "enlarged" heart on autopsy or prenatal ultrasound if no weight was available. Statistical comparisons were carried out on $2 \times 2$ contingency tables with using Fisher's Exact Test of Chi-squared with Pearson correction as appropriate for sample size.

\section{Results}

Structural Cardiac Defects

In the MCTC liveborn twin cohort, structural cardiac defects occurred in 15/124 (12\%) MZ twin subjects (10/90 TTT and $5 / 34$ other MZ twins) compared to only $6 / 298(2 \%) \mathrm{DZ}$ and 9/248 (4\%) UZ subjects. The most common cardiac lesion was VSD accounting for $21 / 30$ or $70 \%$ of structural cardiac malformations. VSD occurred in 12/124 (10\%) of MZ twins, usually as an isolated defect. In twin pairs with TTT, 6/7
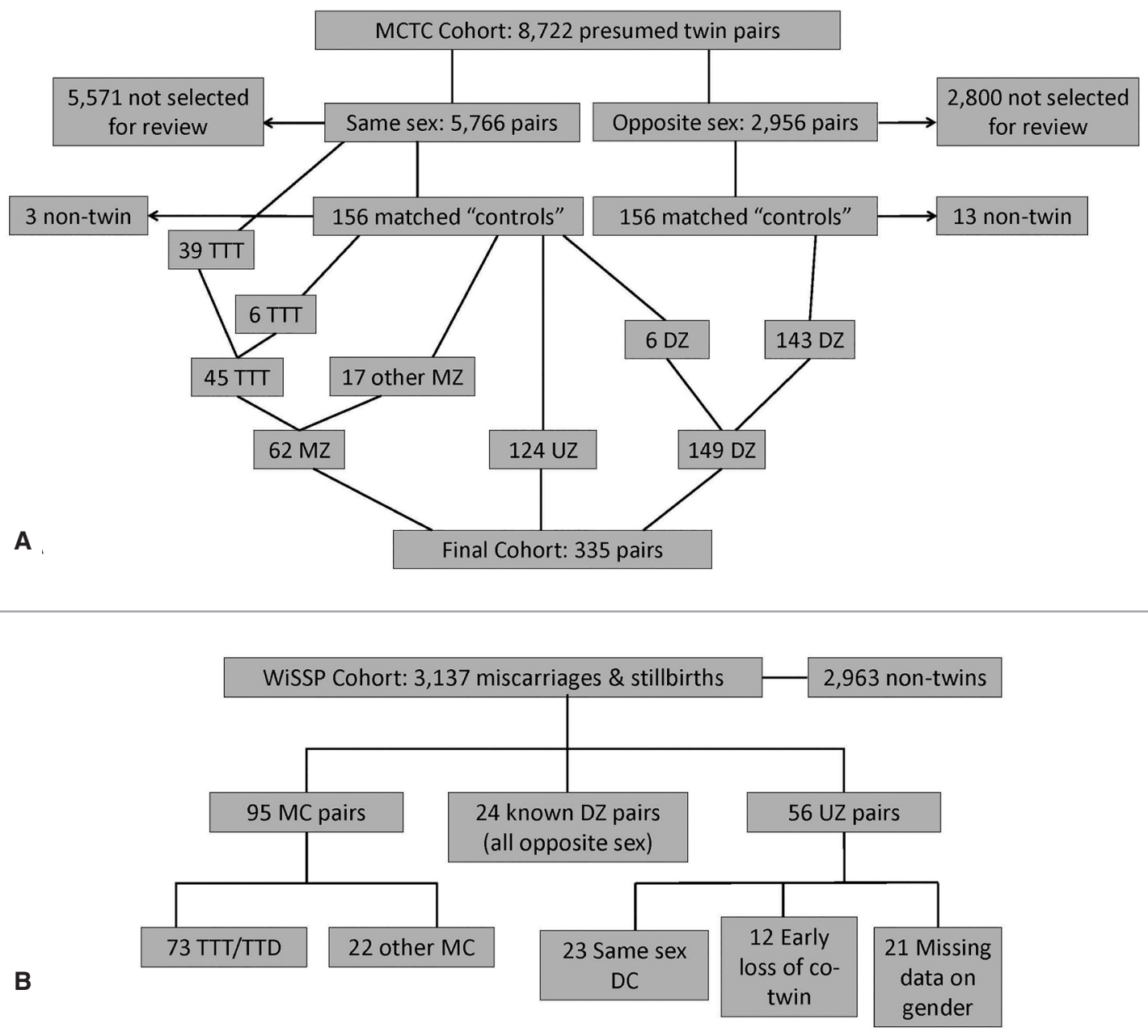

Figure 1. Flow diagrams of the (A) Marshfield Clinic Twin Cohort [MCTC] and (B) Wisconsin Stillbirth Service Program [WiSSP] data abstraction methods. Abbreviations: $\mathrm{DC}=$ dichorionic twins, $\mathrm{DZ}=$ dizygotic twins, $\mathrm{MC}=$ =monochorionic twins, $\mathrm{MZ}=$ monozygotic twins, TTD=twin-twin disruption, TTT=twin-twin transfusion, UZ=unknown zygosity. 
VSDs occurred in the donor twin. Among UZ twins, VSD was less common (2\%) and always occurred in association with other cardiac anomalies, most frequently ASD. In the DZ group, VSD occurred in only 4/298 (1.3\%), usually as part of a recognizable syndrome. More detail regarding structural cardiac anomalies in liveborn twins is provided in Table 1.

In the WiSSP cohort, twinning occurred in 175/3,137 (5.5\%) of referrals, which exceeds the liveborn twinning rate of $3.4 \%$ reported by Martin et al. ${ }^{19}$ The increase in twinning among miscarriages and stillbirths is due primarily to the large number with TTT/TTD (73 pairs compared to only 22 other $\mathrm{MZ}, 56 \mathrm{UZ}$, and $24 \mathrm{DZ}$ pairs). Cardiac anomalies were identified in 11/146 (7.5\%) TTT/TTD infants and 4/112 $(3.6 \%)$ UZ infants. The rate of cardiac anomalies per twin pregnancy $(8.6 \%)$ is comparable to the rate of cardiac anomalies in the entire WiSSP cohort $(8.5 \%)$ reported by Jorgensen et al, ${ }^{20}$ as well as the rate of cardiac anomalies in

Table 1. Structural Cardiac Malformations in Liveborn Twins

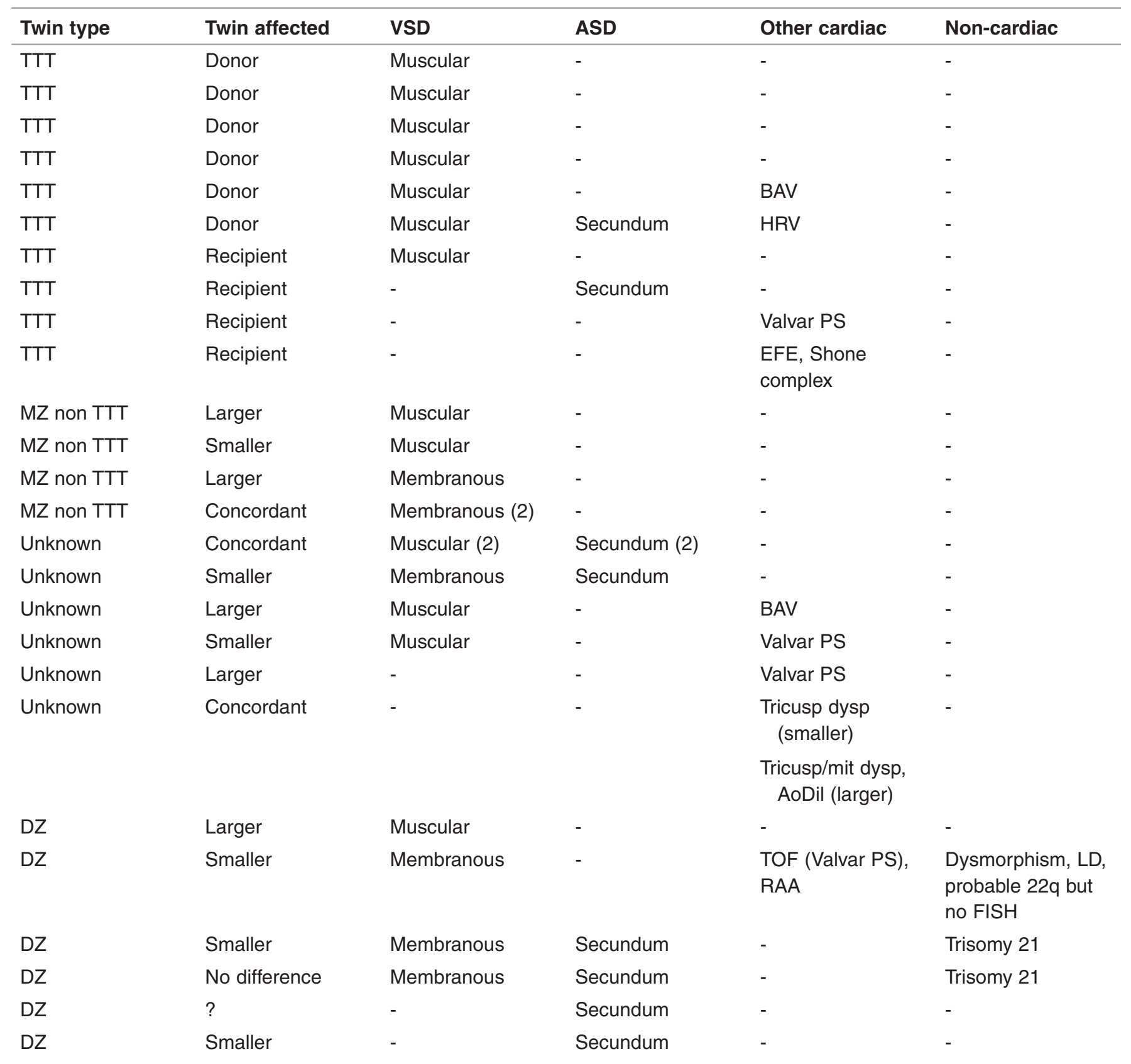

Abbreviations: AoDil=aortic root dilation, $A S D=$ atrial septal defect, $B A V=$ bicuspid aortic valve, $D Z=$ dizygotic, $E F E=e n d o c a r d i a l$ fibroelastosis, FISH=fluorescence in situ hybridization, $\mathrm{HRV}=$ hypoplastic right ventricle, $\mathrm{LD}=$ learning disability, mit dysp=mitral dysplasia, MZ=monozygotic, $\mathrm{PS}=$ =pulmonic stenosis, RAA=right aortic arch, TOF=Tetralogy of Fallot, tricusp dysp=tricuspid dysplasia, TTT=twin-twin transfusion, VSD=ventricular septal defect, -=negative for listed phenotype. 
Table 2. Structural Cardiac Defects in Stillborn and Miscarried Twins

\begin{tabular}{|c|c|c|c|c|c|c|}
\hline $\begin{array}{l}\text { Small-twin } \\
\text { cardiac } \\
\text { abnormalities }\end{array}$ & $\begin{array}{l}\text { Small-twin } \\
\text { other } \\
\text { anomalies }\end{array}$ & $\begin{array}{l}\text { Large-twin } \\
\text { cardiac } \\
\text { abnormalities }\end{array}$ & $\begin{array}{l}\text { Large-twin other } \\
\text { anomalies }\end{array}$ & Gender & Chorion & GA \& outcome \\
\hline Acardia & $\begin{array}{l}\text { Absent head, } \\
\text { upper limbs, \& } \\
\text { thorax }\end{array}$ & $\begin{array}{l}\text { Normal (Exam } \\
\text { limited) }\end{array}$ & $\begin{array}{l}\text { "Amniotic band" on } \\
\text { arm (probably cord } \\
\text { of affected) }\end{array}$ & $\mathrm{F} / \mathrm{F}$ & Mono & 19 wks; Both deceased \\
\hline Acardia & $\begin{array}{l}\text { Absent } \\
\text { calvarium \& } \\
\text { thorax, hydropic }\end{array}$ & $\begin{array}{l}\text { Normal } \\
\text { (Exam limited) }\end{array}$ & $\mathrm{N} / \mathrm{A}$ & $\mathrm{U} / \mathrm{U}$ & Mono & 14 wks; Both deceased \\
\hline Acardia & Amorphous & Normal & $\begin{array}{l}\text { Gastroschisis, } \\
\text { lower limb } \\
\text { reduction, solitary } \\
\text { kidney }\end{array}$ & $F / F$ & Mono & $\begin{array}{l}\mathrm{U}(\text { Larger twin } 870 \mathrm{~g}) \text {; } \\
\text { Both deceased }\end{array}$ \\
\hline Acardia & $\begin{array}{l}\text { Amorphous, } \\
\text { Monosomy } 21\end{array}$ & Normal & $\mathrm{N} / \mathrm{A}$ & $\mathrm{F} / \mathrm{F}$ & Mono & 38 wks; Co-twin liveborn \\
\hline Acardia & $\begin{array}{l}\text { Reduction of } \\
\text { head, upper } \\
\text { limbs, \& thorax, } \\
\text { hydrops }\end{array}$ & Normal & $\begin{array}{l}\text { Intracranial bleed } \\
\text { attributed to } \\
\text { disruption from } \\
\text { deceased twin }\end{array}$ & $\mathrm{F} / \mathrm{F}$ & Mono & 23 wks; Both deceased \\
\hline Acardia & $\begin{array}{l}\text { Amorphous, } \\
\text { edema }\end{array}$ & $\begin{array}{l}\text { Normal } \\
\text { (Exam limited) }\end{array}$ & $\mathrm{N} / \mathrm{A}$ & $\mathrm{U} / \mathrm{U}$ & Mono & 12 wks; Both deceased \\
\hline Acardia & $\begin{array}{l}\text { Amorphous, } \\
\text { edema }\end{array}$ & $\begin{array}{l}\text { Normal } \\
\text { (Exam limited) }\end{array}$ & Cord wrap & $\mathrm{M} / \mathrm{M}$ & Mono & 20 wks; Both deceased \\
\hline Acardia & $\begin{array}{l}\text { Cystic renal } \\
\text { dysplasia, } \\
\text { acephalus, } \\
\text { absent thorax, } \\
\text { limb reduction }\end{array}$ & VSD, valvar PS & $\begin{array}{l}\text { Cystic renal } \\
\text { dysplasia, } \\
\text { cataracts, duodenal } \\
\text { atresia }\end{array}$ & $\mathrm{F} / \mathrm{F}$ & Mono & 29 wks; Both deceased \\
\hline Normal & $\begin{array}{l}\text { Fetus } \\
\text { papyraceus }\end{array}$ & Ectopia cordis & $\begin{array}{l}\text { Thoracoabdominal } \\
\text { defect }\end{array}$ & $\mathrm{M} / \mathrm{M}$ & Mono & 17 wks; Both deceased \\
\hline Normal & $\mathrm{N} / \mathrm{A}$ & ASD & $\begin{array}{l}\text { Plethoric (TTT } \\
\text { recipient) }\end{array}$ & $F / F$ & Mono & 32 wks; Donor survived \\
\hline Ectopia cordis & $\begin{array}{l}\text { Limb body wall } \\
\text { sequence }\end{array}$ & Normal & $\mathrm{N} / \mathrm{A}$ & $\mathrm{F} / \mathrm{F}$ & $\mathrm{Di}$ & 34 wks; Co-twin survived \\
\hline $\begin{array}{l}\text { DORV, TGV, } \\
\text { VSD }\end{array}$ & $\begin{array}{l}\text { Right arm } \\
\text { amelia, left } \\
\text { radial defect, } \\
\text { duodenal } \\
\text { atresia }\end{array}$ & Normal & $\mathrm{N} / \mathrm{A}$ & $\mathrm{M} / \mathrm{M}$ & $\mathrm{Di}$ & $\begin{array}{l}\text { Deceased at } 31 \text { wks; } \\
\text { Co-twin alive at } 34 \text { wks }\end{array}$ \\
\hline$U$ & Early demise & $\begin{array}{l}\text { Complex CHD } \\
\text { (US) }\end{array}$ & Anencephaly & $\mathrm{F} / \mathrm{U}$ & $U$ & $\begin{array}{l}\text { Co-twin died } 9 \text { wks; } \\
27 \text { wks deceased }\end{array}$ \\
\hline $\begin{array}{l}\text { Single ventricle } \\
\text { (US) }\end{array}$ & $\begin{array}{l}\text { Fetus } \\
\text { papyraceus }\end{array}$ & Normal & $\mathrm{N} / \mathrm{A}$ & $\mathrm{M} / \mathrm{M}$ & Di & $\begin{array}{l}\text { Deceased at } 14 \text { wks } \\
34 \text { wks; Co-twin liveborn }\end{array}$ \\
\hline
\end{tabular}

Abbreviations: $\mathrm{ASD}=$ atrial septal defect, $\mathrm{CHD}=$ congenital heart disease, $\mathrm{Di}=$ dichorionic, $\mathrm{DORV}=$ double outlet right ventricle, $\mathrm{F}=$ female, $\mathrm{GA}=$ gestational age in weeks, $\mathrm{M}=$ male, Mono=monochorionic, $\mathrm{N} / \mathrm{A}=$ not applicable, $\mathrm{PS}=\mathrm{pulmonic}$ stenosis, $\mathrm{TGV}=$ transposition of the great vessels, TTT=twin-twin transfusion, VSD=ventricular septal defect, U=unknown, US=prenatal ultrasound, wks=weeks. 
Table 3. Frequency of VSD in Liveborn and Stillborn Twins by Zygosity

\begin{tabular}{llll}
\hline Liveborn twins & & VSD & No VSD \\
& MZ 9.7\% & 12 & 112 \\
& DZ 1.3\% & 4 & 294 \\
& UZ 2.0\% & 5 & 243 \\
Cresti et al ${ }^{21}$ & Italian population 1.0\% & \\
\hline Stillborn twins & & VSD & No VSD \\
& MZ 0.5\% & 1 & 189 \\
& DZ 0\% & 0 & 48 \\
& UZ 0.9\% & 1 & 111 \\
Jorgenson et al & Twins + nontwins 2.6\% & 54 & 2028 \\
\hline
\end{tabular}

MZ monozygotic, DZ dizygotic, UZ unknown zygosity, VSD ventricular septal defect

MC twin pairs $(9.1 \%)$ reported by Manning and Archer. ${ }^{2}$ Occurring in about $1.0 \%$ of livebirths ${ }^{21}$ and $2.6 \%$ of unselected stillbirths, ${ }^{19} \mathrm{VSD}$ was found in only 2/348 stillborn twins, both in association with other malformations. Among stillborn twins, the most frequent defect was acardia (eight fetuses, all with reduction of the head, upper limbs, and/or thorax). One acardiac fetus had monosomy 21, while his pump twin appeared healthy; another shared multiple anomalies with his pump twin. Among the TTT pairs without acardia, there were only two cardiac defects. One larger twin had ectopia cordis presumably due to TTD, and one recipient had a secundum ASD similar to reports of ASD in living recipients of TTT. A more detailed listing of cardiac anomalies in stillborn twins is provided in Table 2 .

\section{Ventricular Septal Defect}

Because the frequencies of VSD are dramatically different from expectations in both liveborn and stillborn groups, we made some comparisons with published data as well as between our liveborn and stillborn cohorts. The occurrence of VSD in 3.1\% of the MCTC cohort is approximately three times a recent estimate for singletons. ${ }^{21}$ In liveborn twins, the highest risk for VSD is in MC pairs, usually as an isolated defect in the smaller twin. Despite the very high frequency of MC twinning and TTT in stillborn and miscarried twin pairs, the prevalence of VSD among stillborn twins in the WiSSP cohort is low, only $0.5 \%$ $(1 / 190)$ compared to $2.6 \%(54 / 2082)$ in an earlier study of the entire cohort ${ }^{20}(P=.02)$. Considering only MC pairs, the excess of VSD is limited to livebirths with a diagnosis of VSD in 9.7\% (12/124) liveborn MC twins contrasting only $0.5 \%$ (1/190) stillborn twins $(P<.0001)$. For detailed information regarding VSD by twin type, please see Table 3.

\section{Cardiomegaly/Cardiomyopathy}

In the liveborn cohort, cardiomegaly/cardiomyopathy was diagnosed in 9/45 (20\%) of the TTT recipients, but did not occur in donors. These nine pairs appeared to have particularly severe effects of TTT, since 4/9 recipients with cardiomegaly also had structural heart defects, and almost half of their donor co-twins had cardiovascular issues (two with structural heart defects and two with anomalies attributable to poor perfusion). None of the DZ or UZ twins had clinically significant ventricular hypertrophy and/or cardiomyopathy on postnatal echocardiography (Table 4).

Among stillborn TTT/TTD pairs, 13/73 larger twins and 0/73 smaller co-twins had cardiomegaly (Table 4). Among the stillborn/miscarried twins with cardiomegaly, 12/13 had structurally normal hearts weighing $>95$ th percentile for gestational age or described as "enlarged" at autopsy, while one had structural heart disease along with extracardiac anomalies, which he shared with his smaller acardiac co-twin. Although the other co-twins had normal hearts, several had other anomalies attributable to poor perfusion. In the UZ group, 2/112 infants had cardiomegaly, including one with a single ventricle who was the larger twin on ultrasound prior to demise and one hydropic infant with a structurally normal heart. Both infants had apparently healthy same sex dichorionic co-twins. None of the stillborn DZ twins had cardiomegaly. Among pairs dying from TTT, 5/9 pairs with documented cardiomegaly had twin-twin body weight differentials $<20 \%$ suggesting that cardiac size may be more sensitive than body weight for identifying pairs with life-threatening TTT.

\section{Discussion}

Our study is the first to specifically examine the type and prevalence of cardiac malformations in stillborn and miscarried twins, and one of very few studies to include follow-up after one year of age for liveborn twins. The detailed manual review of entire medical records provides an opportunity to recognize monozygosity and TTT, even when these are not accurately reflected in the ICD9 or ICD10 diagnostic codes, and to identify individuals with congenital heart disease, even when the diagnosis is made late. It also allows detailed evaluation of twintwin concordance for both cardiac and other anomalies. This approach does, however, result in some limitations. Manual review of medical records is extremely labor intensive, making it impossible to review the entire MCTC cohort. As with any retrospective review, some medical records will be more complete and contain more detail than others. Because most subjects did not undergo genetic zygosity testing, superficial similarity in appearance is not useful in identifying zygosity in stillborn twins, and most medical records of living individuals do not contain data regarding phenotypic similarity such as facial appearance or eye color; MZ pairs are identifiable primarily through placental pathology or due to complications of monochorionicity such as TTT. The discovery of 6 additional TTT pairs and 17 non-TTT MZ pairs among the subset of 153 like-sex pairs reviewed in detail suggests that the entire cohort likely contains about $865 \mathrm{MZ}$ pairs, including 225 TTT pairs that could be identified by manual review. Because manual record review of the 39 electronically identified TTT pairs confirmed that they would have been detected through manual review of the entire MCTC, and the prevalence and types of cardiac 
Table 4. Cardiomegaly/Cardiomyopathy in Stillborn and Liveborn Twins a,b

\begin{tabular}{|c|c|c|c|c|c|c|}
\hline Twin type & $\begin{array}{l}\text { Large-twin } \\
\text { status }\end{array}$ & $\begin{array}{l}\text { Large-twin heart } \\
\text { weightc }^{c}\end{array}$ & $\begin{array}{l}\text { Large-twin } \\
\text { other defects }\end{array}$ & $\begin{array}{l}\text { Small-twin } \\
\text { status }\end{array}$ & $\begin{array}{l}\text { Small-twin heart } \\
\text { weight }^{c}\end{array}$ & $\begin{array}{l}\text { Small-twin other } \\
\text { defects }\end{array}$ \\
\hline TTT & SB & $17.5 \mathrm{~g}(7.1 \mathrm{~g} \pm 2.0 \mathrm{~g})$ & - & SB & $\begin{array}{l}7.5 \mathrm{~g}(7.5 \mathrm{~g} \pm 2.0 \\
\mathrm{g})\end{array}$ & - \\
\hline TTT & SB & "Enlarged" (no wt) & Hydrops & SB & Normal (no wt) & - \\
\hline TTT & SB & $20.0 \mathrm{~g}(16.0 \mathrm{~g} \pm 3.3 \mathrm{~g})$ & - & SB & Data missing & $\begin{array}{l}\text { Arthrogryposis, intestinal } \\
\text { atresia }\end{array}$ \\
\hline TTT & SB & $32.0 \mathrm{~g}(14.8 \mathrm{~g} \pm 3.2 \mathrm{~g})$ & - & SB & $\begin{array}{l}12.0 \mathrm{~g}(14.8 \\
\mathrm{g} \pm 3.2 \mathrm{~g})\end{array}$ & - \\
\hline TTT & SB & $30.0 \mathrm{~g}(11.6 \mathrm{~g} \pm 2.7 \mathrm{~g})$ & - & Survived & Normal (no wt) & Acute tubular necrosis \\
\hline TTT & SB & $5.0 \mathrm{~g}(3.1 \mathrm{~g} \pm 1.1 \mathrm{~g})$ & - & NND & $\begin{array}{l}3.5 \mathrm{~g}(3.1 \mathrm{~g} \pm 1.1 \\
\mathrm{g})\end{array}$ & $\begin{array}{l}\text { Died from extreme } \\
\text { prematurity }\end{array}$ \\
\hline TTT & SB & “Enlarged” (no wt) & Hydrops & Survived & Normal (no wt) & - \\
\hline TTT & SB & $16 \mathrm{~g}(12.6 \mathrm{~g} \pm 2.9 \mathrm{~g})$ & - & SB & $\begin{array}{l}10.0 \mathrm{~g}(12.6 \\
\mathrm{g} \pm 2.9 \mathrm{~g})\end{array}$ & - \\
\hline TTT & SB & $34.0 \mathrm{~g}(19.8 \mathrm{~g} \pm 3.7 \mathrm{~g})$ & - & Survived & Normal (no wt) & - \\
\hline TTT & SB & $\begin{array}{l}15.0 \mathrm{~g}(7.9 \mathrm{~g} \pm 2.1 \mathrm{~g}) \\
\text { VSD, valvar PS }\end{array}$ & $\begin{array}{l}\text { Cystic renal } \\
\text { dysplasia, } \\
\text { cataract, } \\
\text { duodenal } \\
\text { atresia, hydrops }\end{array}$ & SB & Acardia & $\begin{array}{l}\text { Acephaly, absent thorax, } \\
\text { limb reduction, cystic } \\
\text { renal dysplasia }\end{array}$ \\
\hline TTT & SB & $13.0 \mathrm{~g}(7.1 \mathrm{~g} \pm 2.0 \mathrm{~g})$ & - & SB & Normal (no wt) & $\begin{array}{l}\text { Donor of TTT, died at } 20 \\
\text { wks following laser } \\
\text { surgery; delivered with } \\
\text { co-twin at } 28 \text { wks }\end{array}$ \\
\hline TTT & SB & Cardiomegaly on US & $\begin{array}{l}\text { Died at } 22 \text { wks, } \\
\text { fetus } \\
\text { papyraceus }\end{array}$ & Survived & Normal (no wt) & $\begin{array}{l}\text { Severe intrauterine } \\
\text { growth retardation }\end{array}$ \\
\hline TTT & SB & Cardiomegaly on US & $\begin{array}{l}\text { Died at } 25 \text { wks, } \\
\text { hydrops }\end{array}$ & Survived & Normal (no wt) & $\begin{array}{l}\text { Severe intrauterine } \\
\text { growth retardation }\end{array}$ \\
\hline$U$ & SB & $16.0 \mathrm{~g}(10.1 \mathrm{~g} \pm 4.4 \mathrm{~g})$ & Hydrops & Survived & Normal (no wt) & - \\
\hline U & SB & $\begin{array}{l}\text { Single ventricle, } \\
\text { Cardiomegaly on US }\end{array}$ & $\begin{array}{l}\text { Died at } 14-15 \\
\text { wks, fetus } \\
\text { papyraceus }\end{array}$ & Survived & Normal (no wt) & - \\
\hline TTT & Survived & VSD, cardiomyopathy & - & Survived & Normal & - \\
\hline TTT & Survived & PS, RVH & Hydrops & Survived & Normal & - \\
\hline TTT & NND & ASD, BVH & $\begin{array}{l}\text { Died from } \\
\text { intraventricular } \\
\text { hemorrhage }\end{array}$ & Survived & Normal & $\begin{array}{l}\text { Chronic renal failure, } \\
\text { hypertension }\end{array}$ \\
\hline TTT & Survived & $\mathrm{RVH}$ & - & Survived & Normal & - \\
\hline TTT & Survived & $\begin{array}{l}\text { Shone's complex, } \\
\text { cardiomyopathy }\end{array}$ & - & NND & Normal & Cerebellar infarct \\
\hline TTT & Survived & $\mathrm{RVH}$ & - & Survived & VSD & - \\
\hline TTT & Survived & BVH & - & Survived & Normal & - \\
\hline TTT & Survived & $\mathrm{BVH}$ & - & Survived & $\begin{array}{l}\text { VSD, ASD, } \\
\text { hypo-plastic } \\
\text { right ventricle }\end{array}$ & - \\
\hline
\end{tabular}

${ }^{a}$ Cardiac defects other than cardiomyopathy

${ }^{\mathrm{b}}$ Bold text for emphasis

${ }^{\mathrm{c}}$ Mean cardiac weights for gestational age

Abbreviations: $\mathrm{ASD}=$ atrial septal defect, $\mathrm{BVH}=$ biventricular hypertrophy, NND=neonatal death, PS=pulmonic stenosis, $\mathrm{RVH}=$ right ventricular hypertrophy, $\mathrm{SB}=$ stillbirth, TTT=twin-twin transfusion, $\mathrm{U}=$ unknown, US= prenatal ultrasound, $\mathrm{VSD}=$ ventricular septal defect, wks=weeks, wt=weight, -=negative for the listed phenotype. 
malformation appear similar in the 39 electronically identified pairs and the 6 pairs identified through additional manual review, we believe that all 45 TTT pairs included in our study are representative of TTT pairs in the entire MCTC cohort. The enrichment for TTT pairs could have introduced some bias in estimates for risk for MZ pairs, since the number of non-TTT MZ pairs is clearly underestimated, but recalculation excluding the 39 electronically identified TTT pairs yielded a similar (actually slightly higher) prevalence of structural cardiac defects $(7 / 46=15 \%)$ among monochorionic pairs in the same sex "control" group. Therefore we decided to include all identifiable monochorionic pairs in our analysis. The high prevalence of cardiac anomalies applies only to monochorionic pairs raising the possibility that shared circulation may be a risk factor whether or not TTT has been recognized. Dichorionic MZ pairs cannot be clearly distinguished from same-sex DZ pairs and are combined in the unknown zygosity group which has a much lower prevalence of cardiac malformation.

Among the liveborn twins, some cardiac anomalies could have been missed because cardiology evaluation and echocardiogram were performed only when clinically indicated, and therefore, not all of the subjects had echocardiography. In the stillborn group, some cardiac defects could have been missed if small fetal size or severe maceration (as in a fetus papyraceous) limited evaluation of the heart or if the parents declined autopsy. Being retrospective and initially exploratory, this study was designed primarily to provide information on the type, concordance, and frequency of congenital heart disease in understudied twin populations. The high frequency of VSD in living TTT and other MC twins, especially in comparison to previous studies based on prenatal ultrasound, indicates a need for more careful postnatal follow-up for MZ twins, particularly MC pairs. The stark difference between the liveborn and stillborn groups, however, prompts speculation about possible mechanisms that could lead to the observed patterns.

Because acardia is easily explained as a complication of $\mathrm{MC}$ twinning, the high frequency in stillborn and miscarried MC twins is expected; however, the increased prevalence of VSD among liveborn twins, particularly MC pairs, requires further explanation. As the most common structural cardiac anomaly in the MCTC twins, VSD occurs at an incidence of $3.1 \%$, which is approximately three times a recent estimate for singletons. ${ }^{21}$ Among liveborn twins, the highest risk for VSD is in MC pairs; however, despite a very high proportion of MC pairs among stillborn and miscarried twins, the prevalence of VSD is lower than expected. If the $9.7 \%$ frequency of VSD in liveborn MC twins was applied to the 190 stillborn twins, one would expect 18 twins with VSD, but only one VSD was observed. Different methods of ascertainment cannot explain this discrepancy, since it seems unlikely that echocardiography of symptomatic infants only in the liveborn cohort would be more efficient than autopsy in the stillborn cohort for detection of VSD. Though not intrinsically lethal, VSD occurred in $2.6 \%$ (54/2082) of the entire WiSSP cohort, ${ }^{20}$ usually as part of a fatal multiple anomaly syndrome. If this frequency of VSD was applied to the 350 stillborn twins in the WiSSP cohort, we would expect 9 fetuses with VSD, but only 2 were observed. As observed in the stillborn singletons, we would expect that most of these VSDs would occur in association with other more lethal anomalies. To explain the dearth of VSD in stillborn MZ twins, we need to consider a mechanism that causes VSD in liveborn MC twins with or without TTT but not in severely affected pairs dying from TTT or other complications of MC twinning. We propose a mechanism of inequality of the twinning process that results in cardiac abnormalities for the smaller twin ranging from acardia in the most severe cases to VSD in less severely affected liveborn MC twins.

Inequality of the twinning process and the type and distribution of vascular anastomoses contribute to the severity of complications in MC twins. Arteriovenous anastomoses, present in almost all MC pregnancies, are deep and unidirectional and cause complications if imbalance in the size and/or number of anastomoses results in a net transfusion. ${ }^{22}$ To prevent shunting through arteriovenous anastomoses, laser surgery for TTT should obliterate entire cotyledons, but following successful laser surgery, scarring is frequently only superficial, which suggests plasticity of placental development continuing throughout pregnancy. ${ }^{15}$ To explain this observation, Benirschke ${ }^{15}$ proposed a model in which varying degrees of unequal division of the inner cell mass followed by differential perfusion result in a spectrum of phenotypes ranging from entirely normal $\mathrm{MC}$ twins to selective intrauterine growth restriction, TTT, twin reversed arterial perfusion, and acardia.

We propose an extension of Benirschke's model, whereby an initially unequal division of the inner cell mass results in a smaller twin with fewer precursor cells. ${ }^{15}$ In contrast to a localized loss of cardiac progenitors that can be compensated by regeneration, ${ }^{23}$ a generalized deficiency of precursor cells may result in delayed growth and development for all organs including the heart and placenta with no extra cells available to replace those missing from vital organs. Due to reduced blood volume and delayed or less robust cardiac development, the small fetus has lower blood pressure, which delays the folding of capillaries to form placental villi thereby further reducing placental share and contributing to the development of unbalanced arteriovenous anastomoses. Delayed placental development may also result in hypoxia of the smaller fetus as noted by Yang et al. ${ }^{24}$ Placental insufficiency as a mechanism for congenital heart disease may also be applicable to dichorionic twins, regardless of zygosity, if there is severe asymmetry of placental development as briefly discussed by Bahtiyar. $^{4}$

Acardia, which is the most frequent cardiac anomaly in stillborn and miscarried twins, fits easily into Benirschke's model as a complication resulting from decreased placental share if both arterioarterial and venovenous anastomoses are present, creating bidirectional connections between the fetal circulations, which, in the presence of a significant differential in blood pressure, may result in reversed perfusion with 
regression of cardiac development in the smaller twin along with a risk of high output heart failure and life-threatening hydrops fetalis in the larger pump twin. Mathematical models based on relative size of the twins can predict onset of reversed perfusion/acardia in the small twin ${ }^{25}$ and hydrops in the pump twin. ${ }^{26}$ In our cohort, however, the death of $6 / 8$ pump twins from other causes prior to onset of hydrops demonstrates other risks inherent in severely unequal twinning. The very early cessation of cardiac development prevents structural evaluation of the transiently beating heart in the "acardiac" fetus.

In the absence of arterioarterial and venovenous anastomoses, reversal of circulation is not possible, but imbalance in placental share and perfusion via arteriovenous anastomoses may result in TTT. Van dem Wijngaard et $\mathrm{al}^{27}$ proposed a positive feedback mechanism where renin/angiotensin mediators produced in response to hypotension and hypovolemia in the donor twin reach the recipient via placental anastomoses further exacerbating existing hypervolemia and hypertension and contributing to high output heart failure and hydrops. Recipient twins, with or without hydrops, are at risk for acquired cardiac lesions including cardiomyopathy and ROTO due to venous hypertension and high cardiac output. In our group of severely affected TTT pairs in which at least one infant was stillborn (excluding acardia), 12/87 (14\%) of the recipients had significant cardiomyopathy. Among the liveborn pairs with presumably less severe TTT, 9/45 (20\%) of the recipients had clinically recognized cardiomyopathy in the newborn period.

The increased incidence of structural cardiac malformations, especially VSD, in donor twins requires an earlier developmental explanation, since cardiac morphogenesis is usually completed before TTT becomes clinically evident. We postulate that in addition to causing acardia or TTT, underlying inequality in the twinning process adversely affects cardiac development early in the embryonic period by at least two possible mechanisms: (1) lack of progenitor cells in the smaller fetus, and (2) decreased oxygenation of the smaller twin. In an embryo with deficient cardiac progenitors and limited availability of stem cells for regeneration, deficient or delayed development of the second heart field could plausibly contribute to future septal defects in the donor heart. ${ }^{28}$ Furthermore, given the developing septum is sensitive to hypoxia, ${ }^{29}$ limitation of oxygenation in a fetus with decreased placental share may contribute to failure of septal development. The observation of decreased placental and fetal weight in liveborn singletons with major $\mathrm{VSD}^{30}$ provides further evidence for interaction between placental and ventricular septal development. If deficiency in cardiac progenitors and/ or hypoxia due to placental insufficiency contributes significantly to defective septal development, an increase in VSD affecting the smaller twin in severely unbalanced MC twin pairs would be expected. Among stillborn pairs, however, an increase in VSD might be masked by even more severe anomalies such as acardia.
While acardia occurs too early for effective intervention, earlier recognition and treatment of less severe degrees of unequal placental perfusion may be lifesaving for twins who do not yet meet the classical criteria for TTT. Cardiomegaly, even in the absence of major differences in body weight, may be a marker for life-threatening TTT. Due to the high prevalence of structural cardiac anomalies in liveborn MC twins, observation for possible cardiac defects, especially VSD, is important at all stages of pregnancy and should continue after delivery.

\section{Acknowledgements}

The authors would like to thank Dr. Karl Degenhardt for helpful suggestions; Emily Andreae, PhD, for manuscript editing assistance; and Marie Fleisner for manuscript preparation.

\section{References}

1. Karatza AA, Wolfenden JL, Taylor MJ, Wee L, Fisk NM, Gardiner HM. Influence of twin-twin transfusion syndrome on fetal cardiovascular structure and function: Prospective casecontrol study of 136 monochorionic twin pregnancies. Heart. 2002;88:271277.

2. Manning N, Archer N. A study to determine the incidence of structural congenital heart disease in monochorionic twins. Prenat Diagn. 2006;26:1062-1064.

3. Manning N. The influence of twinning on cardiac development. Early Hum Dev. 2008;84:173-179.

4. Bahtiyar MO, Dulay AT, Weeks BP, Friedman AH, Copel JA. Prevalence of congenital heart defects in monochorionic/ diamniotic twin gestations: A systematic literature review. J Ultrasound Med. 2007;26:1491-1498.

5. Hardin J, Carmichael SL, Selvin S, Lammer EJ, Shaw GM. Increased prevalence of cardiovascular defects among 56,709 California twin pairs. Am J Med Genet A. 2009;149A:877-886.

6. Al Rais F, Feldstein VA, Srivastava D, Gosnell K, Moon-Grady AJ. Monochorionic twins discordant for congenital heart disease: A referral center's experience and possible pathophysiologic mechanisms. Prenat Diagn. 2011;31:978-984.

7. Springer S, Mlczoch E, Krampl-Bettelheim E, MailáthPokorny M, Ulm B, Worda C, Worda K. Congenital heart disease in monochorionic twins with and without twin-to-twin transfusion syndrome. Prenat Diagn. 2014;34:994-999.

8. Michelfelder E, Tan X, Cnota J, Divanovic A, Statile C, Lim FY, Crombleholme T. Prevalence, spectrum, and outcome of right ventricular outflow tract abnormalities in twin-twin transfusion syndrome: A large, single-center experience. Congenit Heart Dis. 2014;10:209-218.

9. Manning N, Archer N. Cardiac Manifestations of Twin-to-Twin Transfusion Syndrome. Twin Research and Human Genetics, 2016;19:246-254.

10. Herberg U, Gross W, Bartmann P, Banek CS, Hecher K, Breuer J. Long term cardiac follow up of severe twin to twin transfusion syndrome after intrauterine laser coagulation. Heart. 2006;92:95-100.

11. van den Boom J, Battin M, Hornung T. Twin-twin transfusion syndrome, coarctation of the aorta and hypoplastic aortic arch: A case series report. J Pediatr Child Health. 2010;46:76-79.

12. Thacker D, Gruber PJ, Weinberg PM, Cohen MS. Heterotaxy syndrome with mirror image anomalies in identical twins. Congenit Heart Dis. 2009;4:50-53.

13. Weber MA, Sebire NJ. Genetics and developmental pathology of twinning. Semin Fetal Neonatal Med. 2010;15:313-318. 
14. Noli L, Capalbo A, Ogilvie C, Khalaf Y, Ilic D. Discordant growth of monozygotic twins starts at the blastocyst stage: A case study. Stem Cell Reports. 2015;5:946-953.

15. Benirschke K. The monozygotic twinning process, the twintwin transfusion syndrome and acardiac twins. Placenta. 2009;30:923-928.

16. Herskind AM, Pedersen DA, Christensen K. Increased Prevalence of Congenital Heart Defects in Monozygotic and Dizygotic Twins. Circulation 2013;128:1182-1188.

17. Mayer J, Kitchner T, Ye Z, Zhou Z, He M, Schrodi SJ, Hebbring SJ. Use of an electronic medical record to create the Marshfield Clinic twin/multiple birth cohort. Genet Epidemiol. 2014;38:692-698.

18. Maroun LL, Graem N. Autopsy standards of body parameters and fresh organ weights in nonmacerated and macerated human fetuses. Pediatr Dev Pathol. 2005;8:204-217.

19. Martin JA, Hamilton BE, Osterman MJ, Driscoll AK, Matthews TJ. Births final data for 2015. Nat Vital Stat Rep. 2017;66:1.

20. Jorgensen M, McPherson E, Zaleski C, Shivaram P, Cold C. Stillbirth: the heart of the matter. Am J Med Genet A. 2014;164A:691-699.

21. Cresti A, Giordano R, Koestenberger M, Spadoni I, Scalese M, Limbruno U, Falorini S, Stefanelli S, Picchi A, De Sensi F, Malandrino A, Cantinotti M. Incidence and natural history of neonatal isolated ventricular septal defects: Do we know everything? A 6-year single-center Italian experience followup. Congenit Heart Dis. 2018;13:105-112.

22. Lanna MM, Consonni D, Faiola S, Schena V, Ratti M, Ferrazzi E, Rustico MA. Color-dye injection of monochorionic placentas and correlation with pregnancy complications. Placenta. 2015;36:1095-1099.

23. Sturzu AC, Rajarajan K, Passer D, Plonowska K, Riley A, Tan TC, Sharma A, Xu AF, Engels MC, Feistritzer R, Li G, Selig MK, Geissler R, Robertson KD, Scherrer-Crosbie M, Domian IJ, Wu SM. Fetal mammalian heart generates a robust compensatory response to cell loss. Circulation. 2015;132:109121.

24. Yang LL, Shao H, Yuan PB, Guo XY, Zang XW, Zhao YY. Expressions of HIF-1? and its target gene in monochorionic twin placentas with twin-twin transfusion syndrome. Beijing Da Xue Xue Bao Yi Xue Ban. 2011;43(6):792-797. [Article in Chinese]

25. van Gemert MJ, Wijngaard JP, Paarlberg KM, Gardiner HM, Nikkels PG. Acardiac twin pregnancies part IV: Acardiac onset from unequal embryonic splitting simulated by a fetoplacental resistance model. Birth Defects Res. 2017;109:211223.

26. van Gemert MJ, Ross MG, Nikkels PG, Wijngaard JP. Acardiac twin pregnancies part III: Model simulations. Birth Defects Res A Clin Mol Teratol. 2016;106:1008-1015.

27. van den Wijngaard JP, Umur A, Krediet RT, Ross MG, van Gemert MJ. Modeling a hydropic recipient twin in twin-twin transfusion syndrome. Am J Physio Regul Integr Comp Physiol. 2005;288:R779-R814.

28. Schleich JM, Abdulla T, Summers R, Houyel L. An overview of cardiac morphogenesis. Arch Cardiovasc Dis. 2013;106:612623.

29. Yuan X, Qi H, Li X, Wu F, Fang J, Bober E, Dobreva G, Zhou Y, Braun T. Disruption of spatiotemporal hypoxic signaling causes congenital heart disease in mice. J Clin Invest. 2017; 127:2235-2248.

30. Matthiesen NB, Henriksen TB, Agergaard P, Gaynor JW, Bach CC, Hjortdal VE, Ostergaard JR. Congenital Heart Defects and Indices of Placental and Fetal Growth in a Nationwide Study of 924422 Liveborn Infants. Circulation. 2016;134:1546-1556.

\section{Author Affiliations}

Elizabeth McPherson, MD*; Colin Korlesky, BS广; and Scott Hebbring, $P h D^{*}$

*Center for Human Genetics, Marshfield Clinic Research Institute, Marshfield, Wisconsin USA

tDepartment of Pediatrics, University of Wisconsin School of Medicine and Public Health, Madison, Wisconsin, USA 